\section{RSP}

http://www.rsp.fsp.usp.br/
Revista de Saúde Pública

\title{
Socioeconomic, hygienic, and sanitation factors in reducing diarrhea in the Amazon
}

\author{
Katiuscia Shirota Imada', Thiago Santos de Araújo', Pascoal Torres Muniz', Valter Lúcio de Pádua" \\ ' Centro de Ciências da Saúde e do Desporto. Universidade Federal do Acre. Rio Branco, AC, Brasil \\ " Departamento de Engenharia Sanitária e Ambiental. Escola de Engenharia. Universidade Federal de Minas \\ Gerais. Belo Horizonte, MG, Brasil
}

\section{ABSTRACT}

OBJECTIVE: To analyze the contributions of the socioeconomic, hygienic, and sanitation improvements in reducing the prevalence of diarrhea in a city of the Amazon.

METHODS: In this population-based cross-sectional study, we analyzed data from surveys conducted in the city of Jordão, Acre. In 2005 and 2012, these surveys evaluated, respectively, 466 and 826 children under five years old. Questionnaires were applied on the socioeconomic conditions, construction of houses, food and hygienic habits, and environmental sanitation. We applied Pearson's Chi-squared test and Poisson regression to verify the relationship between origin of water, construction of homes, age of introduction of cow's milk in the diet, place of birth and the prevalence of diarrhea.

RESULTS: The prevalence of diarrhea was reduced from $45.1 \%$ to $35.4 \%$. We identified higher probability of diarrhea in children who did not use water from the public network, in those receiving cow's milk in the first month after birth, and in those living in houses made of paxiúba. Children born at home presented lower risk of diarrhea when compared to those who were born in hospital, with this difference reversing for the 2012 survey.

CONCLUSIONS: Sanitation conditions improved with the increase of bathrooms with toilets, implementation of the Programa de Saúde da Família (PSF - Family Health Program), and water treatment in the city. The multivariate regression model identified a statistically significant association between use of water from the public network, construction of houses, late introduction of cow's milk, and access to health service with occurrence of diarrhea.

DESCRIPTORS: Child, Preschool. Diarrhea, epidemiology. Basic Sanitation. Water Supply. Domestic Effuents. Community Development. Socioeconomic Factors.

\footnotetext{
Received: 25 Jun 2015

Approved: 10 Jul 2016

How to cite: Imada KS, Araújo

TS, Muniz PT, Pádua VL.

Socioeconomic, hygienic, and

sanitation factors in reducing

diarrhea in Amazon. Rev Saude

Publica. 2016:50:77.

Copyright: This is an open-access article distributed under the terms of the Creative Commons Attribution License, which permits unrestricted use, distribution, and reproduction in any medium, provided that the original author and source are credited.

Katiuscia Shirota Imada Centro de Ciência da Saúde e do Desporto

em Nutrição Distrito Industria 69920-900 Rio Branco, AC, Brasil E-mail: k_shirota@hotmail.com
} 
a Brasil. Law no. 11,445 , of January 5, 2007. Establishes national guidelines for basic sanitation; changes Laws no. 6,766 (December 19, 1979), 8,036 (May 11, 1990), 8,666 (June 21, 1993), 8,987 (February 13, 1995); repeals Law no. 6,528 (May 11, 1978); and creates other measures. Diario Oficial Uniao. 11 jan 2007.

${ }^{\text {b } T e i x e i r a ~ J C . ~ A s s o c i a c ̧ a ̃ o ~ e n t r e ~}$ cenários de saneamento e indicadores de saúde em crianças. Estudo de áreas de assentamento subnormal em Juiz de Fora, MG [these]. Belo Horizonte (MG): Escola de Engenharia da UFMG; 2003.

cWorld Health Organization (WHO). Diarrhea: why children are still dying and what can be done. Geneva: World Health Organization; 2009 [cited 2014 Oct 31]. Available from: http://apps.who.int/ iris/bitstream/10665/44174/ 1/9789241598415_eng.pdf

¿ Brasil. Constituição da República Federativa do Brasil (1988). Brasília (DF): Senado; 1988

e Instituto Brasileiro de Geografia e Estatística. Censo demográfico 2010 [cited 2013 Aug 14]. Available from: http://www. ibge.gov.br/home/estatistica/ populacao/censo2010

${ }^{\mathrm{f}}$ Atlas do Desenvolvimento Humano no Brasil. Índice de desenvolvimento humano municipal (IDHM). Brasília (DF): PNUD; 2013.

\section{INTRODUCTION}

Sanitation, recognized as an important health promotion strategy, figures on the international agenda among the eight Millennium Development Goals, whose aim to halve the population without access to drinking water was reached in advance. However, $11.0 \%$ of the world's population still remains without access to drinking water. Overcoming this challenge requires facing technological, political, and managerial barriers, which are even more complex in the Amazon because of natural obstacles.

In Brazil, basic sanitation is a right ensured by the Constitution and defined by the Law $11,445 / 2007$, which establishes the national guidelines for sanitation, defined as the set of services, infrastructure, and facilities of water supply, sewage system, urban cleaning, urban drainage, solid waste and rainwater management ${ }^{\text {a }}$. These services promote the improvement of the quality of life of the population, reflecting directly on child health, with reduction of child mortality and of diarrheal, parasitic, and skin diseases. Besides, they protect the health of the population, minimizing the consequences of poverty and also protecting the environment $\mathrm{t}^{\mathrm{b}}$.

Diarrhea is a serious public health problem related to hygiene conditions and quality of water used 9 . It is the second most common cause of childhood deaths, representing around 1.5 million deaths/year in children under five years ${ }^{c}$. There are many determinant factors ${ }^{13}$; about $88 \%$ of diarrhea deaths are attributed to unsafe drinking water, inadequate sewage system, and precarious hygiene $e^{c}$. Thus, measures to prevent infant diarrhea must be prioritized as key strategy for improving child health. Among the measures, are the following: provision of water, both in quantity and quality; removal and treatment of domestic sewage; and promotion of sanitation actions in all communityc. The infrastructure sector must supply treated water, sewage system, solid waste cleaning and collection, and rainwater drainage and management, with participation of the public health sector and community, as foreseen in the Federal Constitution of $1988^{\mathrm{d}}$.

In some isolated and poorer localities of the State of Acre, as is the case of Jordão, the expansion of the supply network of drinking water and sewage system and also of medical care occurred slowly because of logistical difficulties, especially for the rural population. This study aimed to analyze the contribution of sanitation actions such as drinking water supply, construction of houses, introduction of cow's milk, and place of birth on the reduction of the prevalence of diarrhea in children under five in the urban and rural area of the city.

\section{METHODS}

This population-based cross-sectional study used data from two surveys conducted in the city of Jordão, Acre, in the years of 2005 and 2012, which evaluated, respectively, 466 and 826 children under five in the urban and rural area ${ }^{8}$.

Jordão is located at $700 \mathrm{~km}$ from Rio Branco, in the State of Acre, and was created in 1992, after separation from the city of Tarauacá, located in Vale do Juruá. It has an area of $5,429 \mathrm{~km}^{2}$, bathed by the rivers Jordão and Tarauacá, and borders the cities of Marechal Thaumaturgo, Feijó, and Tarauacá, and the country Peru. The population of the city in the 2010 Census was of 6,577 inhabitants, with 2,272 in the urban area and 4,305 in the rural area ${ }^{e}$. It is one of the most isolated cities of the State for having access only by water and air, contributing to the maintenance of high prices of goods and food. Until 2005, it did not have water treatment nor sewage system.

In the context of Amazonian and Acre reality, Jordão is considered one of the poorest cities of the Country. In 2000, its Human Development Index (HDI) was of 0.222 and, in 2010, it increased to $0.469^{f}$. However, this is still considered a very low HDI, figuring among the 10 lowest of Brazil. 
In both surveys, the information of the characteristics of houses, environmental sanitation, and health were obtained by questionnaires, conducted by properly trained researchers. The respondent was an adult responsible by the home, who was asked to characterize the occurrence of diarrhea and whether the child(ren) of the house presented in the last 15 days more than four bowel movements/day of liquid consistency or with increase in volume. For the socioeconomic assessment, we evaluated the presence of electrical energy; benefit from Bolsa Familia Program; maternal education; and household income. Regarding the houses, we considered the type of construction material of the house, roof, and floor, and the total rooms. Concerning infant feeding, we considered the period of introduction of cow's milk. About the place of birth, we considered whether it occurred at home or in hospital. To evaluate environmental sanitation, we considered the type of toilet in the home and the destination of trash, as well as the origin, frequency of lack, and type of treatment carried out on drinking water.

For the categorical variables, we applied Pearson's Chi-squared test and linear trend test, which consider the exposure level at the moment of identifying differences between the two surveys. To obtain the crude and adjusted association measures and assessment of the association strength between independent variables and outcome, we used Poisson regression with robust error estimation (Stata 9.0).

The projects were approved by the Research Ethics Committees of Fundação Hospitalar Estadual do Acre and Universidade Federal do Acre (UFAC) (Opinions 042/2005 and 23107.017408/2010-16). The guardians of the children signed the informed consent form.

\section{RESULTS}

Comparing the 2005 and 2012 surveys, the prevalence of diarrhea decreased from $45.1 \%$ (95\%CI 40.5-49.7) to 35.4\% (95\%CI 32.1-38.7), respectively (Figure). This reduction was expressive in the urban area. Regarding hospitalizations by diarrhea, there was an increase from $4.5 \%$ to $10.7 \%$ between 2005 and 2012. At the same time, the rate of hospitalization by diarrhea increased in the urban area of the city $(\mathrm{p}<0.001)$.

Table 1 presents data on sociodemographic and environmental conditions for the years 2005 and 2012. There was no change in the proportion of families with children under five years with access to electrical energy and in the proportion of minimum wages received by households. However, the proportion of families benefited by the Family Allowance Program increased, rising from $23.9 \%$ in 2005 to $53.9 \%$ in 2012. The maternal education level increased, reducing illiteracy in 5.4 percentage points. We observed a significant reduction, especially in the urban area, of homes built with paxiúba ${ }^{g}$, as well as increased use of wood in the construction of houses and on floors. Considering the type of roof of the houses, straw was the material more employed. There was no significant increase in the number of rooms of the houses. Regarding the place of birth of the children, there was a reduction of births in hospital and increase in home childbirth. The introduction of cow's milk on infant feeding in the first month of life increased, with values of $43.0 \%$ and $24.8 \%$ in 2005 and 2012, respectively.

Table 2 describes the transformations in health conditions that took place in Jordão between the surveys analyzed. A significant portion of households with children under five years had no toilet at home: $36.5 \%$ in 2005 and $34.8 \%$ in 2012 . However, there was statistically significant improvement in the replacement of latrines for ceramic toilets in the houses between 2005

g Popular name of a palm of the Arecaceae family; it occurs in Central and South America and in Brazil, and it is used for building houses and making floors. and 2012. In $65.6 \%$ of houses equipped with bathroom, this was built outside the house. This variable was only evaluable in 2012, since in 2005 it was not part of the questionnaire applied. Of the families that had no bathroom, $94.4 \%$ reported defecating in the backyard, bush, or open area and $5.6 \%$, in the neighbors' toilet. 


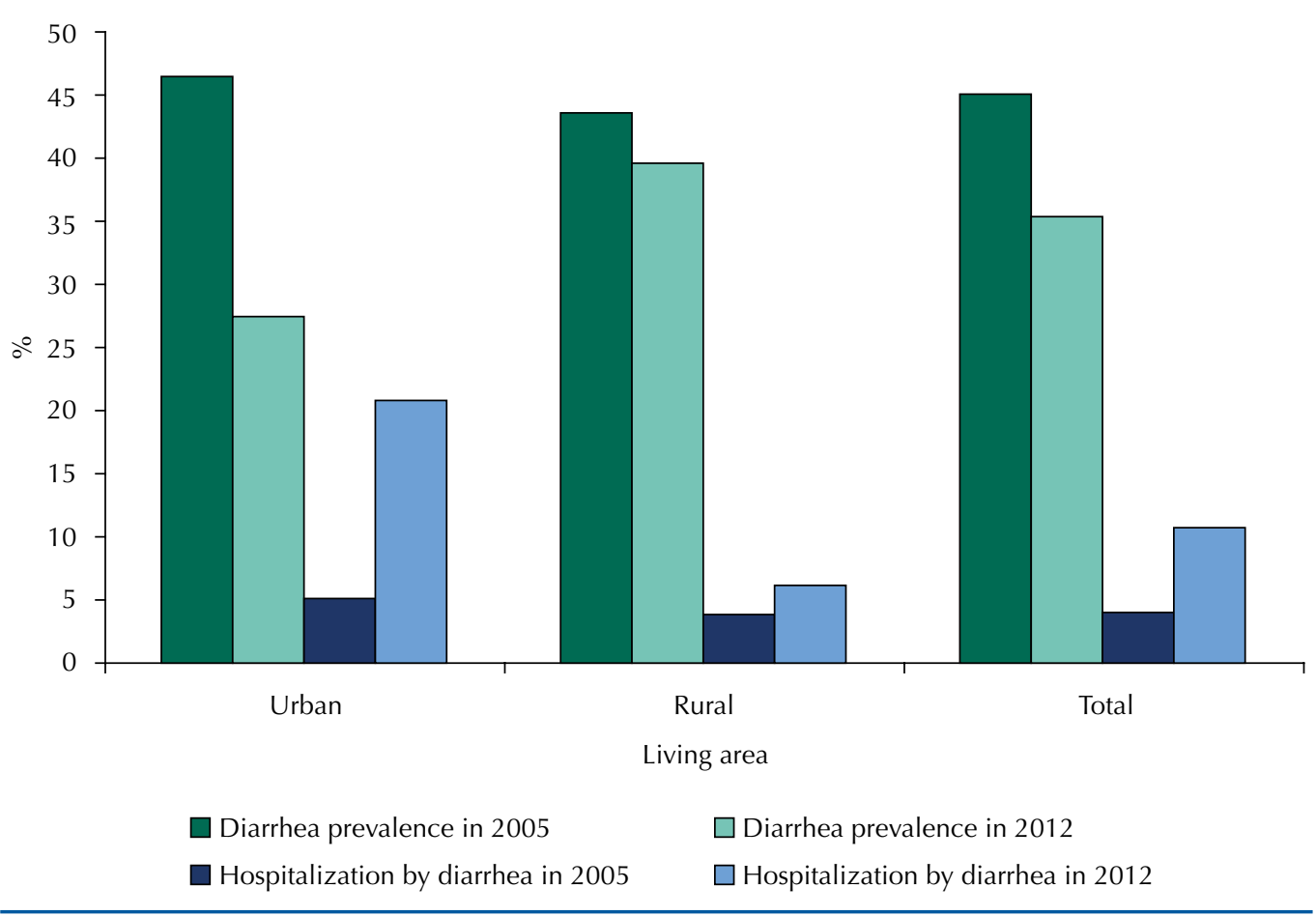

Figure. Prevalence of diarrhea in past 15 days and hospitalization by this harm in children of the urban and rural area of the city of Jordão, Acre, 2005 and 2012.

Regarding the origin of water (Table 2) used in houses in 2005 and 2012, the use of river water predominated, representing $48.2 \%$ and $56.8 \%$, respectively. More than a third of the houses did not present home connections of the public water supply in 2012. In 2005 and 2012, respectively, $72.5 \%$ and $62.1 \%$ of participants reported that water never lacks and $15.8 \%$ and $20.4 \%$, that it rarely lacks. The chlorination of water at the houses was the treatment technique most reported by families with children under five in both surveys. A portion of the population uses water without any treatment before consumption, accounting for $31.1 \%$ of children under five years old. Concerning the destination of trash, there was no significant change, with predominance of public collection in $36.8 \%$ and $38.8 \%$ in 2005 and 2012 , respectively. Regarding the destination of sewage, in $2005,46.0 \%$ of the houses did it by open pit, $28.4 \%$ by cesspit, and $14.2 \%$ by septic tank. In 2012, cesspit and open pit were used by, respectively, $39.8 \%$ and $34.7 \%$ of houses.

Table 3 provides information about the presence of insects and rodents in the houses, as well as the care of families with food handling. Concerning flies, $28.0 \%$ of families classified as high the presence of this insect at home. The presence of cockroaches took place on $89.7 \%$ of houses, with $42.8 \%$ of families classifying as high the infestation of this insect. In relation to rodents, $78.8 \%$ reported presence, with $27.5 \%$ of houses showing high infestation. Regarding hygienic care during food handling, $88.7 \%$ reported washing their hands before handling food that will be consumed by children. Concerning the hygiene of fruits and vegetables eaten raw, only $23.8 \%$ of families washed them with treated water, $43.4 \%$ washed with untreated water, and $25.3 \%$ did not wash the fruits and vegetables consumed by children under five.

Table 4 describes the association between diarrhea and the four determining factors selected: origin of water, type of house, age of introduction of cow's milk, and place of birth for the years 2005 and 2012. About the origin of the water used, we identified, in both surveys, more probability of diarrhea among children who did not use water from the public supply network. In 2005, this risk was 1.38 times and in 2012, 1.60 times higher, when compared to children who used well water. 
Table 1. Socio-environmental characteristics of houses, place of birth, and introduction of cow's milk in the diet of children under five years old living in the urban and rural area of the city of Jordão, Acre, 2005 and 2012

\begin{tabular}{|c|c|c|c|c|c|}
\hline \multirow{2}{*}{ Variable } & \multicolumn{2}{|c|}{2005 survey } & \multicolumn{2}{|c|}{2012 survey } & \multirow{2}{*}{$\mathbf{p}$} \\
\hline & $\mathbf{n}$ & $\%$ & $\mathbf{n}$ & $\%$ & \\
\hline Electrical energy & & & & & 0.304 \\
\hline Yes & 160 & 35.2 & 303 & 38.3 & \\
\hline No & 295 & 64.8 & 489 & 61.7 & \\
\hline Total & 455 & 100 & 792 & 100 & \\
\hline Family Allowance Program & & & & & $<0.001$ \\
\hline Yes & 110 & 23.9 & 437 & 53.9 & \\
\hline No & 351 & 76.1 & 373 & 46.1 & \\
\hline Total & 461 & 100 & 810 & 100 & \\
\hline Mother's education level & & & & & 0.017 \\
\hline Illiterate & 79 & 17.4 & 99 & 12.0 & \\
\hline $1-4$ years & 214 & 47.0 & 411 & 49.8 & \\
\hline $5-8$ years & 96 & 21.2 & 186 & 22.5 & \\
\hline 9-11 years & 57 & 12.6 & 96 & 11.6 & \\
\hline$\geq 12$ years & 8 & 1.8 & 34 & 4.1 & \\
\hline Total & 454 & 100 & 826 & 100 & \\
\hline Household income (minimum wages) & & & & & 0.545 \\
\hline $0-0.5$ & 191 & 41.8 & 367 & 45.2 & \\
\hline $0.5-0.9$ & 88 & 19.3 & 138 & 17.0 & \\
\hline $1-1.9$ & 122 & 26.7 & 219 & 27.0 & \\
\hline$\geq 2$ & 56 & 12.5 & 88 & 10.8 & \\
\hline Total & 457 & 100 & 812 & 100 & \\
\hline Type of house & & & & & $<0.001$ \\
\hline Masonry & 10 & 2.3 & 46 & 5.6 & \\
\hline Processed wood & 221 & 50.1 & 537 & 65.7 & \\
\hline Paxiúba & 210 & 47.6 & 235 & 28.7 & \\
\hline Total & 441 & 100 & 818 & 100 & \\
\hline Type of roof & & & & & $<0.001$ \\
\hline Asbestos & 55 & 12.2 & 26 & 3.2 & \\
\hline Zinc or aluminum & 126 & 28.1 & 334 & 41.1 & \\
\hline Straw & 268 & 59.7 & 452 & 55.7 & \\
\hline Total & 449 & 100 & 812 & 100 & \\
\hline Type of floor & & & & & $<0.001$ \\
\hline Wood & 243 & 52.5 & 549 & 67.1 & \\
\hline Ceramics or cement & 2 & 0.4 & 13 & 1.6 & \\
\hline Paxiúba & 218 & 47.1 & 256 & 31.3 & \\
\hline Total & 463 & 100 & 818 & 100 & \\
\hline Number of rooms & & & & & $<0.001$ \\
\hline 1 & 50 & 10.8 & 171 & 21.2 & \\
\hline 2 & 105 & 22.7 & 158 & 19.5 & \\
\hline 3 & 307 & 66.5 & 480 & 59.3 & \\
\hline Total & 462 & 100 & 809 & 100 & \\
\hline Introduction of cow's milk & & & & & $<0.001$ \\
\hline 1-29 days & 188 & 43.0 & 202 & 24.8 & \\
\hline 30-730 days & 74 & 16.9 & 570 & 69.9 & \\
\hline Never drank cow's milk & 175 & 40.1 & 43 & 5.3 & \\
\hline Total & 437 & 100 & 815 & 100 & \\
\hline Place of birth & & & & & 0.001 \\
\hline House & 298 & 35.5 & 442 & 55.1 & \\
\hline Hospital & 164 & 64.5 & 360 & 44.9 & \\
\hline Total & 462 & 100 & 802 & 100 & \\
\hline
\end{tabular}


Table 2. Sanitation conditions of houses with children under five years old living in the urban and rural area of the city of Jordão, Acre, 2005 and 2012.

\begin{tabular}{|c|c|c|c|c|c|}
\hline \multirow[t]{2}{*}{ Variable } & \multicolumn{2}{|c|}{$\begin{array}{c}\text { Year of survey } \\
2005 \\
\end{array}$} & \multicolumn{2}{|c|}{$\begin{array}{c}\text { Year of survey } \\
2012 \\
\end{array}$} & \multirow{2}{*}{$\mathbf{p}$} \\
\hline & $\mathbf{n}$ & $\%$ & $\mathbf{n}$ & $\%$ & \\
\hline Toilet & & & & & $<0.001$ \\
\hline Absence & 169 & 36.5 & 284 & 34.8 & \\
\hline Ceramic & 99 & 21.4 & 276 & 33.8 & \\
\hline Wood & 195 & 42.1 & 257 & 31.4 & \\
\hline Total & 463 & 100 & 817 & 100 & \\
\hline \multicolumn{6}{|l|}{ Origin of water } \\
\hline Rain & 4 & 0.9 & 18 & 2.2 & 0.001 \\
\hline Public network & 160 & 34.6 & 239 & 29.8 & \\
\hline Well or spring & 76 & 16.4 & 90 & 11.2 & \\
\hline River & 223 & 48.2 & 456 & 56.8 & \\
\hline Total & 463 & 100 & 803 & 100 & \\
\hline \multicolumn{6}{|l|}{ Frequency of water shortage } \\
\hline Never & 335 & 72.5 & 504 & 62.1 & $<0.001$ \\
\hline Rarely & 73 & 15.8 & 166 & 20.4 & \\
\hline Often & 54 & 11.7 & 142 & 17.5 & \\
\hline Total & 462 & 100 & 812 & 100 & \\
\hline Treatment of drinking water & & & & & $<0.001^{*}$ \\
\hline Boiled/Filtered and boiled & 61 & 13.3 & 48 & 6.1 & \\
\hline Filtered & 20 & 4.4 & 32 & 4.1 & \\
\hline Chlorinated at home & 244 & 53.3 & 449 & 57.5 & \\
\hline Mineral & 2 & 0.4 & 9 & 1.2 & \\
\hline Untreated & 131 & 28.6 & 243 & 31.1 & \\
\hline Total & 458 & 100 & 781 & 100 & \\
\hline Destination of trash & & & & & 0.675 \\
\hline Collection & 168 & 36.4 & 304 & 38.8 & \\
\hline Buried/Burned/Thrown into river & 163 & 35.4 & 273 & 34.8 & \\
\hline Thrown in open area & 130 & 28.2 & 207 & 26.4 & \\
\hline Total & 461 & 100 & 784 & 100 & \\
\hline Destination of sewage & & & & & $<0.001$ \\
\hline Septic tank & 65 & 14.2 & 124 & 15.6 & \\
\hline Cesspit & 130 & 28.4 & 317 & 39.8 & \\
\hline Open pit & 210 & 46.0 & 276 & 34.7 & \\
\hline Others & 52 & 11.4 & 79 & 9.9 & \\
\hline Total & 457 & 100 & 796 & 100 & \\
\hline
\end{tabular}

* Test did not include Mineral category.

In relation to the type of house, even not reaching statistical significance, this variable was kept in the model because of the significant changes observed in the construction of houses in the comparison between 2005 and 2012. This variable suggests higher probability of developing diarrhea in children living in households of paxiúba, which reached 1.21 times when compared to the value observed among children living in masonry or processed wood houses, in 2012.

In 2005, children receiving cow's milk in the first month after birth showed probability of developing diarrhea 1.3 times higher than that of children who had never consumed cow's milk and a probability $17.0 \%$ higher than the observed between those who received cow's milk after 30 days. This same trend was observed in 2012, reaching twice the probability of 
Table 3. Animal infestation and hygiene care in houses with children under five years old living in the urban and rural area of the city of Jordão, Acre, 2012.

\begin{tabular}{|c|c|c|}
\hline \multirow{2}{*}{ Variable } & \multicolumn{2}{|c|}{ Year of survey 2012} \\
\hline & $\mathbf{n}$ & $\%$ \\
\hline \multicolumn{3}{|l|}{ Insects and rodents } \\
\hline \multicolumn{3}{|l|}{ Flies } \\
\hline Not present & 103 & 12.9 \\
\hline Low & 357 & 44.8 \\
\hline Average & 114 & 14.3 \\
\hline High & 223 & 28.0 \\
\hline Total & 797 & 100 \\
\hline \multicolumn{3}{|l|}{ Cockroaches } \\
\hline Not present & 84 & 10.3 \\
\hline Low & 268 & 32.8 \\
\hline Average & 115 & 14.1 \\
\hline High & 349 & 42.8 \\
\hline Total & 816 & 100 \\
\hline \multicolumn{3}{|l|}{ Rat } \\
\hline Not present & 162 & 21.2 \\
\hline Low & 269 & 35.2 \\
\hline Average & 123 & 16.1 \\
\hline High & 210 & 27.5 \\
\hline Total & 764 & 100 \\
\hline \multicolumn{3}{|l|}{ Washes hands when handling food } \\
\hline Yes & 708 & 88.7 \\
\hline No & 90 & 11.3 \\
\hline Total & 798 & 100 \\
\hline \multicolumn{3}{|l|}{ Care with raw fruits and vegetables } \\
\hline Washed (treated water) & 163 & 23.8 \\
\hline Washed (untreated water) & 297 & 43.4 \\
\hline Does not wash & 173 & 25.3 \\
\hline Does not consume raw fruits and vegetables & 51 & 7.5 \\
\hline Total & 684 & 100 \\
\hline
\end{tabular}

Table 4. Prevalence (\%) and relative risk of diarrhea in children under five years old according to variables of origin of water, type of house, age of introduction of cow's milk, and place of birth. Jordão, Acre, 2005 and 2012.

\begin{tabular}{|c|c|c|c|c|c|c|}
\hline \multirow{2}{*}{ Variable } & \multicolumn{3}{|c|}{ Year of survey 2005} & \multicolumn{3}{|c|}{ Year of survey 2012} \\
\hline & $\mathbf{n}$ & $\%$ & $\mathbf{R R}^{\mathbf{b}}$ & $\mathbf{n}$ & $\%$ & $\mathbf{R R}^{\mathrm{c}}$ \\
\hline Water & & & $p=0.025$ & & & $p=0.024$ \\
\hline Public network ${ }^{\mathrm{a}}$ & 41 & 36.9 & 1 & 67 & 28.5 & 1 \\
\hline Well or river & 114 & 51.1 & 1.38 & 14 & 60.9 & 1.6 \\
\hline Others & 55 & 42.6 & 1.17 & 200 & 37.0 & 1.01 \\
\hline Type of house & & & $p=0.511$ & & & $p=0.081$ \\
\hline Masonry or processed wood & 107 & 43.7 & 1 & 187 & 32.1 & 1 \\
\hline Paxiúba & 103 & 47.2 & 1.08 & 103 & 43.8 & 1.21 \\
\hline Age of introduction of cow's milk & & & $p=0.022$ & & & $p=0.034$ \\
\hline Never drank & 71 & 40.6 & 1 & 10 & $23.3 \%$ & 1 \\
\hline $1-29$ days & 95 & 50.5 & 1.31 & 73 & 36.1 & 1.90 \\
\hline 30-730 days & 32 & 43.2 & 1.17 & 208 & 36.5 & 1.76 \\
\hline Place of birth & & & $p=0.031$ & & & $p=0.009$ \\
\hline Hospital or maternity & 83 & 50.6 & 1 & 101 & 28.1 & 1 \\
\hline House & 126 & 42.3 & 0.78 & 185 & 41.9 & 1.40 \\
\hline
\end{tabular}

a Only in the urban area.

${ }^{\mathrm{b}}$ RR: Relative risk of diarrhea adjusted to the other variables of the Poisson multiple regression table.

c Year 2005: water from well and without treatment. 
occurrence of diarrhea episode of the first group and 1.76 times in relation to the second. Regarding the place of birth, in 2005, children born at home presented lower risk of diarrhea when compared to those who were born in hospital, with this difference reversing in 2012.

\section{DISCUSSION}

In the seven years between the two surveys, we identified a high prevalence of diarrhea among children living in the city, but with a 9.7\% reduction in the occurrence of this harm. Cesário et al. ${ }^{3}$, in a study of diarrhea prevalence in a teaching-health-care district of Rio Branco, Acre, in 2003, found prevalence of diarrhea of $33.3 \%$ in children under five years old. Benício et al. ${ }^{2}$ estimated the prevalence of diarrhea in children under five years of 10.5\% in Brazil, of 12.5\% in the North and, in São Paulo, of 4.7\% considering the several socioeconomic strata and of $9.3 \%$ in children of underprivileged families. Vasquez et al. ${ }^{14}$ found $10.2 \%$ of prevalence of diarrhea in children of Pernambuco and $16.9 \%$ in the metropolitan region of Recife. Kariuki et al. ${ }^{6}$ (2012) reported that, in Turkana District, Kenya, the prevalence of diarrhea in 2007 was $43.7 \%$ and, in $2008,30.7 \%$. We observed that the prevalence of diarrhea in children of Jordão was superior to that of all researches mentioned.

Despite this high prevalence, we observed a reduction of this harm, at the same time with an increase in hospitalizations by diarrhea, between 2005 and 2012. Both situations can be a consequence of the implementation of the Family Health Program (PSF), in 2007, and of the inauguration of a Family hospital in the city, in 2008, which facilitated the access of the population to medium complexity care.

Jordão still has a rural population higher than the urban, which justify many houses not having electrical energy and, consequently, the advantages brought by this resource. This reality of the interior of the Amazon differs sharply from that experienced in the Center-South of Brazil, in which even small towns far from urban centers present an urban population greater than the rural and largest coverage of electrical energy services ${ }^{1}$.

Regarding social aid, the increase of families benefited by the Family Allowance Program was substantial, especially in the rural area of the city, increment factor for the acquisition of consumer goods or improving food quality.

We verified a change in the structure of houses, with increased use of processed wood for construction and floor, as well as on the number of rooms of the houses. This scenario shows improvement in the purchasing power of the population in this city and may indicate better infrastructure conditions of families with children under five, which certainly contribute to reducing exposures to diseases, including diarrhea.

As a way to evaluate the access to health services, we chose the variable of place of birth. The increase of home childbirth can be assigned to the fact that the population of the city is predominantly rural and, after the implantation of PSF, to increased prenatal care, training of midwives, and encouraging natural childbirth.

The introduction of cow's milk on infant feeding is an important variable to evaluate the care and knowledge of the mother about the importance of breastfeeding. We observed late introduction of cow's milk on infant feeding, decreasing the risk of diarrhea. These data indicate the importance of complementary feeding and breastfeeding practices for prevention of health problems in the early years of life. Cow's milk is responsible for $20.0 \%$ of food allergies ${ }^{7}$; in addition, the digestion of the protein of cow's milk is difficult in children, increasing the risk of diarrhea. The increase of the mother's education level and PSF actions may have contributed to late introduction of cow's milk on infant feeding.

A significant portion of the children still had no toilet in their homes, even with the construction of home health facilities in partnership with the Fundação Nacional de Saúde (FUNASA - National Health Foundation), which promoted the replacement of latrines for 
ceramic toilets in the houses between 2005 and 2012. There is a predominance of toilets outside the houses, which is typical of the rural area. This variable was only evaluable in 2012, since in 2005 it was not part of the questionnaire applied. In African countries, the use of latrine or outhouse is universalized ${ }^{13}$ : approximately $92.4 \%$ in Uganda, $95.0 \%$ in Kenya, and 99.5\% in Tanzania. The latrines in the urban area are built of permanent materials and, in rural areas, of mud and branches, to prevent fecal material from reaching the domestic environment ${ }^{13}$.

We observe the importance of the program for distribution of sodium hypochlorite in the city, since more than $50.0 \%$ of respondents rely on this resource for the treatment of drinking water. The Ministry of Health and State and Municipal Secretariats recommend the use of sodium hypochlorite solutions for disinfection of water in regions where there is no sanitation, because it is a simple, low cost, and effective preventive measure for fighting waterborne diseases ${ }^{\mathrm{h}}$. The type of water treatment used in Jordão differs from other locations, such as in the city of Iporanga, São Paulo, where 69\% of houses evaluated have piped water and, of these houses, $22.0 \%$ filter drinking water, $15.0 \%$ boil it, and $62.0 \%$ do not perform any treatment ${ }^{5}$.

Regarding the destination of trash, there was no improvement in collection and proper disposal in landfill between 2005 and 2012, a condition that contributes to the presence and proliferation of insects and rodents, which is sustained by the high presence of insects in the houses. In fact, the presence of flies is associated with infant diarrhea ${ }^{11}$.

Concerning the destination of sewage, in 2005, open pit and cesspit predominated, situations that favor the contamination of the environment near the houses and interfere in health conditions of children ${ }^{10}$. The lack of sewage disposal system interferes directly in children health for polluting the environment and allowing the transmission of excreta-related diseases, mainly parasitic ones. The disposal of excreta in open land or street is a risk for helminthiasis and, consequently, for other waterborne diseases, as diarrheai.

We verified the care with the hygiene of hands before food preparation, but a small portion did not perform such care, contributing to the risk of contamination during food preparation. Regarding fruits and vegetables consumed raw, an expressive portion washed them, but with untreated water. As the water came predominantly from rivers, this practice can offer risk of disease transmission, especially diarrhea. The water used for consumption in rural and urban areas, in this study, came from well or river, representing a 38.0 and $60.0 \%$ higher risk (in 2005 and 2012) for diarrhea than the consumption of water from the public network. However, the risks found for diarrhea were lower than those found by Teixeira and Heller ${ }^{11}$ in areas of subnormal settlement in the city of Juiz de Fora. Washing hands with water and soap can reduce $48.0 \%$ of the risk of diarrhea; improving water quality, $17.0 \%$ of risk; and proper sewage collection, $36.0 \%$ of risk ${ }^{4}$.

The sanitation conditions in the city presented an expressive improvement, with increase in the number of bathrooms with toilets, implementation of water treatment in the urban area of the city, increased maternal education, and access to health services. The multivariate regression model identified a statistically significant association between use of water from the public network, type of house, late introduction of cow's milk, and access to health service with occurrence of diarrhea. Although the sanitary transformations that took place in Jordão were important on the occurrence of diarrhea, water supply and sewage systems remain not universalized. Expansion must be prioritized, since this service has not yet achieved a large portion of the population living in rural areas.

\section{REFERENCES}

1. Azeredo CM, Cotta RMM, Schott M, Maia TM, Marques ES. Avaliação das condições de habitação e saneamento: a importância da visita domiciliar no contexto do Programa de Saúde da Família. Cienc Saude Colet. 2007;12(3):743-53. DOI:10.1590/S1413-1232007000300025 
2. Benicio MHD'A, Monteiro CA. Tendência secular da doença diarréica na infância na cidade de São Paulo (1984-1996). Rev Saude Publica. 2000;34(6 Suppl):83-90. DOI:10.1590/S0034-89102000000700011

3. Cesario RR, Tavares-Neto J. Prevalência de diarréia na população do Distrito Docente-Assistencial do Tucumã, Rio Branco, Estado do Acre, Brasil, em 2003. Epidemiol Serv Saude. 2006;15(3):19-28. DOI:10.5123/S1679-49742006000300003

4. Cairncross S, Hunt C, Boisson S, Bostoen K, Curtis V, Fung ICH, Schmidt WP. Water, sanitation and hygiene for the prevention of diarrhoea. Int J Epidemiol. 2010;39(suppl 1):i193-205. DOI:10.1093/ije/dyq035

5. Giatti LL, Rocha AA, Santos FA, Bitencourt SC, Pieroni SRM. Condições de saneamento básico em Iporanga, Estado de São Paulo. Rev Saude Publica. 2004;38(4). DOI:10.1590/S0034-89102004000400014

6. Kariuki JC, Macambo KJ, Njeruh MF, Muchiri EM, Nzioka SM, Kariuki S. Effects of hygiene and sanitation interventions on reducing diarrhoea prevalence among children in resource constained communities: case study of Turkana Dsitrict, Kenya. J Community Health. 2012;37(6):1178-84. DOI:10.1007/s10900-012-9560-1.

7. Monte CMG, Giugliani ERJ. Recomendações para alimentação complementar da criança em aleitamento materno. J Pediatr (Rio J). 2004;80(5 Suppl):s131-41. DOI:10.1590/S0021-75572004000700004

8. Oliveira CSM, Cardoso MA, Araújo TS, Muniz PT. Anemia em crianças de 6 a 59 meses e fatores associados no Município de Jordão, Estado do Acre, Brasil. Cad Saude Publica. 2011;27(5):1008-20. DOI:10.1590/S0102-311X2011000500018

9. Özkan S, Tüzün H, Görer N, Ceyhan M, Aycan S, Albayrakv S et al. Water usage habits and the incidence of diarrhea in rural Ankara, Turkey. Trans Soc Trop Med Hyg. 2007;101(11):1131-5. DOI:10.1016/j.trstmh.2007.05.011

10. Paz MGA, Almeida MF, Günther WMR. Prevalência de diarréia em crianças e condições de saneamento e moradia em áreas periurbanas de Guarulhos, SP. Rev Bras Epidemiol. 2012;15(1):188-97. DOI:10.1590/S1415-790X2012000100017

11. Teixeira JC, Heller L. Fatores ambientais associados à diarreia infantil em áreas de assentamento subnormal em Juiz de Fora, Minas Gerais. Rev Bras Saude Mater Infant. 2005;5(4):449-55. DOI:10.1590/S1519-38292005000400008

12. Trevett AF, Carter RC, Tyrrel SF. The importance of domestic water quality management in the context of fecal-oral disease transmission. I Water Health. 2005;3(3):259-70. DOI:10.2166/wh.2005.037

13. Tumwine JK, Thompson J, Katui-Katua M, Mujwahuzi M, Johnstone N, Porras I. Sanitation and hygiene in urban and rural households in East Africa. Int I Environ Health Res. 2003;13(2):107-15. DOI:10.1080/0960312031000098035

14. Vázquez ML, Mosquera M, Cuevas LE, González ES, Veras ICL, Luz EO et al. Incidência e fatores de risco de diarreia e infecções respiratórias agudas em comunidades urbanas de Pernambuco, Brasil. Cad Saude Publica. 1999;15(1):163-72. DOI:10.1590/S0102-11X1999000100016

Funding: Brazilian Ministry of Health, Conselho Nacional de Desenvolvimento Científico e Tecnológico (CNPq), Secretaria de Estado da Saúde do Acre (SESACRE), Fundação de Tecnologia do Acre (FUNTAC - Processo 0037309-4/2010).

Authors' Contribution: Design, planning of the study, and data collection:IKS, ATS. Data analysis and interpretation: IKS, ATS. Preparation and/or writing of the manuscript: IKS, ATS. Critical review of the manuscript: MPT, PVL. All authors have approved the final version of the manuscript and are publicly responsible for its content.

Conflict of Interest: The authors declare no conflict of interest. 